\title{
Pengembangan Model Perilaku Mengebut di Indonesia serta Rekomendasi Pencegahannya
}

\author{
Lintang Maulida Sekar Bawono ${ }^{1 *}$, Fitri Trapsilawati ${ }^{2}$ \\ ${ }^{1,2}$ Program Studi Teknik Industri, Universitas Gadjah Mada, Yogyakarta, Indonesia \\ (*lintangmaulida@mail.ugm.ac.id)
}

\begin{abstract}
Abstrak - Menurut data dari Kepolisian Republik Indonesia, 61\% kasus terjadinya kecelakaan adalah karena faktor manusia. Kementerian Perhubungan (Kemenhub) juga mencatat bahwa sedikitnya 2-3 orang meninggal dunia per harinya akibat kecelakaan lalu lintas dimana pada posisi pertama kecelakaan disebabkan oleh pengendara sepeda motor. Land Transport Safety Authority (LTSA) pada tahun 2001 juga menemukan bahwa mengebut (speeding) menjadi faktor utama dalam kematian pengendara kendaraan bermotor. Oleh karena itu, perlu dilakukannya penelitian yang dapat mengungkapkan faktor-faktor yang mempengaruhi perilaku mengebut sehingga mekanisme pencegahan perilaku tersebut dapat dibuat. Sebuah kuesioner dikembangkan sebagai instrumen penelitian berdasarkan Theory of Planned Behaviour (TPB), Drivers Behaviour Questionnaire (DBQ), Classical Deterrence Theory (CDT) dan Revised Reinforcement Sensitivity Theory (r-RST). Terdapat 317 responden yang mengisi kuesioner tersebut. Metode analisis yang digunakan untuk mengolah data tersebut adalah dengan menggunakan Partial Least Square Structural Equation Modelling (PLS-SEM). Hasil dari 317 pengendara di Indonesia menunjukkan bahwa Perceived Behavioural Control (PBC) merupakan variabel yang paling mempengaruhi niat seseorang untuk melakukan perilaku mengebut. Sehingga, salah satu rekomendasi pencegahan berdasarkan hasil tersebut adalah dengan memberikan hambatan agar pengendara tidak merasa termotivasi untuk melakukan perilaku mengebut.
\end{abstract}

Kata kunci: perilaku mengebut; Structural Equation Modelling; Theory of Planned Behaviour

\section{PENDAHULUAN}

Masyarakat Indonesia cenderung mengandalkan kendaraan bermotor apabila ingin bepergian. Hal ini terbukti oleh Indonesia yang menduduki peringat ketiga sebagai pasar terbesar di dunia, setelah India dan Cina, akibat penjualan kendaraan bermotor pada tahun 2018 (Mola dkk., 2019). Dalam penggunaan kendaraan bermotor, risiko mengalami kecelakaan lalu lintas tidak dapat dihindarkan. Terdapat peningkatan jumlah kecelakaan kendaraan bermotor tiap tahunnya. Berdasarkan Badan Pusat Statistik (2018) peningkatan per tahunnya mencapai 3,3\%. Di Yogyakarta sendiri, pada tahun 2019 jumlah kecelakaan yang terjadi adalah 5.944 kasus dari yang sebelumnya 5.061 kasus. Adanya pandemi Covid-19 memang mengurangi jumlah kasus kecelakan bermotor hingga 7.565 kasus pada tahun 2020 karena adanya pembatasan aktivitas. Akan tetapi, Adira Insurance mengatakan bahwa angka ini masih relatif tinggi jika dibandingkan dengan penurunan volume kendaraan di jalan raya berdasarkan data dari Polda Metro Jaya bidang Lalu Lintas. Oleh karena itu, dapat dikatakan bahwa risiko kecelakaan lalu lintas tidak hanya bergantung pada situasi lalu lintas saja. Direktur Lalu Lintas Jalan Kementerian Perhubungan Darat, Sigit Irfansyah, mengatakan bahwa hampir tiga kasus kecelakaan terjadi di Indonesia setiap jam nya. Kementerian Perhubungan (Kemenhub) juga mencatat bahwa sedikitnya 2-3 orang meninggal per jamnya akibat kecelakaan lalu lintas dimana pada posisi pertama kecelakaan disebabkan oleh pengendara sepeda motor (Samudra \& Wijaya, 2020). Hal ini berarti pada setiap kasus kecelakaan setidaknya ada satu orang meninggal dunia.

Faktor utama terjadinya kecelakaan adalah perilaku pengendara yang agresif dan tidak patuh terhadap aturan yang ada (Indriastuti \& Sulistio, 2010). Menurut data dari Kepolisian Republik Indonesia, 61\% faktor penyebab terjadinya kecelakaan adalah karena faktor manusia (kemampuan serta karakter pengemudi). Perilaku dan karakter pengendara telah lama diamati oleh para peneliti untuk mengetahui penyebab pengendara melakukan perilaku agresif. Diantara perilaku-perilaku pengendara agresif atau tidak taat aturan yang ada, perilaku yang paling menonjol adalah perilaku speeding (mengebut) dan overtaking (mendahului kendaraan lain). Ketika pengendara mendahului kendaraan lainnya, pengendara secara otomatis mengebut. Oleh karena itu, penelitian oleh Atombo dkk. (2016) menyebutkan bahwa mengebut merupakan pelanggaran yang paling sering dilakukan pengendara dibandingkan overtaking. Selain itu, Land Transport Safety Authority (LTSA) pada tahun 2001 juga menemukan bahwa mengebut (speeding) adalah penyebab kecelakaan kendaraan yang berujung fatal. Sehingga, dalam pencegahan perilaku mengebut, sikap, persepsi, atau faktor yang mendasari 
perilaku tersebut perlu diketahui agar mekanisme pencegahan dapat dibentuk dengan tepat untuk menekan pertambahan jumlah kecelakaan kendaraan bermotor, terutama di Indonesia.

Berdasarkan uraian tersebut, permasalahan yang diangkat pada penelitian ini adalah jumlah kasus kecelakaan di Indonesia masih relatif tinggi tiap tahunnya dan penyebab utama kecelakaan kendaraan bermotor yang berujung fatal adalah perilaku mengebut. Oleh karena itu, tujuan adanya penelitian ini adalah sebagai berikut:

1) Merancang model yang dapat menjelaskan faktor-faktor yang mempengaruhi perilaku mengebut di Indonesia.

2) Mengetahui rekomendasi yang tepat untuk menekan perilaku mengebut oleh pengendara di Indonesia.

\section{STUDI LITERATUR}

TPB adalah model yang dikembangkan oleh Ajzen sejak tahun 1991. Terkait penelitian yang hanya berfokus pada perilaku mengebut, di Oman, Boisson dkk. (2019) melakukan penelitian yang berfokus pada kelompok pengendara mobil generasi terbaru. Penelitian tersebut menemukan bahwa sikap terhadap mengebut, norma subjektif, dan kontrol perilaku yang dirasakan pengendara dapat memprediksi niatan pengendara untuk melakukan perilaku mengebut. Javid dan Al-Hashimi (2020) melakukan penelitian yang sama. Penelitian tersebut menegaskan bahwa metode TPB dapat dilakukan untuk memprediksi perilaku mengebut dan menemukan bahwa budaya mengebut dan sikap terhadap mengebut (attitudes toward speeding) memiliki hubungan yang positif yang signifikan terhadap niat dan perilaku mengebut. Sedangkan kontrol perilaku yang dirasakan (perceived behavioural control) memiliki hubungan yang negatif yang signifikan. Penelitian lainnya oleh Forward (2009) menggunakan TPB. Hasil dari penelitian tersebut mengatakan bahwa pengalaman dan sikap (attitudes) pada komponen TPB berkontribusi besar pada model untuk memperkirakan niat seseorang dalam melakukan perilaku mengebut. Akan tetapi kontribusi sikap tersebut bertentangan dengan penelitian oleh Wallén Warner dan Åberg (2008) yang menemukan bahwa komponen TPB yang berkontribusi paling besar dalam memprediksi niat mengebut adalah subjective norm dan perceived behavioural control. Begitu pula dengan penelitian oleh Boisson dkk. (2019).

Terkait DBQ, di Kuwait, Al-Matawaha dkk. (2020) telah menggunakan DBQ untuk mengetahui hubungan antara perilaku yang berkaitan dengan kecepatan terhadap kasus kecelakaan. Berdasarkan hasil penelitian tersebut, perilaku mengebut dan pelanggaran terhadap peraturan lalu lintas memainkan peran yang penting pada kecelakaan, terutama pengendara berusia muda (18-29 tahun). Umur merupakan faktor yang paling mempengaruhi perilaku mengebut pengendara. Penelitian oleh Atombo dkk. (2016) mengatakan bahwa variabel deliberate violations dan mistakes memiliki hubungan yang positif terhadap niat seseorang dalam melakukan perilaku mengebut dan variabel unintended violation memiliki hubungan yang lemah terhadap niat seseorang dalam melakukan perilaku mengebut. Akan tetapi, berdasarkan Atombo dkk., komponen dari TPB memiliki kemampuan yang lebih untuk dapat mempresiksi niat seseorang dalam melakukan perilaku mengebut daripada komponen dari DBQ.

Penelitian terkait pencegahan perilaku mengebut telah banyak dilakukan dengan mengikuti teori Classical Deterrence Theory (CDT) yang menyatakan bahwa kejahatan atau pelanggaran dapat dicegah oleh ancaman hukuman (legal sanctions). Penelitian oleh Trapsilawati dkk. (2021) menemukan bahwa sanksi hukum memiliki hubungan yang negatif terhadap perilaku mengebut sehingga sanksi hukum merupakan metode yang efektif untuk mencegah mengebut. Sama seperti penelitian oleh Truelove dkk. (2017) yang mengatakan bahwa sanksi hukum maupun sanki non-hukum dapat mempengaruhi kecepatan yang diambil oleh pengendara. Variabel pada CDT yaitu certainty (khususnya personal certainty) dan severity memiliki hubungan yang negatif terhadap perilaku mengebut. Hal ini berarti semakin pengendara merasa sanksi yang diberikan akan sangat berdampak dan pasti akan didapatkan oleh mereka, semakin kecil kemungkinan pengendara melakukan perilaku mengebut. Penelitian oleh Truelove dkk. (2020) juga masih mendapatkan hal yang sama akan tetapi ternyata hal tersebut berubah-ubah seiring waktu dengan variabel yang paling sering berubah yaitu variabel certainty. Selaras dengan pernyataan oleh Homel (1988) bahwa kunci dari model CDT adalah paparan yang konstan dan berulang terhadap faktor pencegah (sanksi hukum).

Revised Reinforcement Sensitivity Theory (r-RST) adalah metode yang dapat digunakan untuk mengetahui sensitivitas seseorang pada hukuman (punishment) dan pada penghargaan (reward). Dalam pengukurannya, teori ini dapat menggunakan kuesioner Sensitivity to Punishment and Sensitivity to Reward (SPSRQ) atau menggunakan kuesioner Reinforcement Sensitivity Theory - Personality Questionnaire (RST-PQ). Kemudian 
dalam pengaplikasiannya r-RST dapat berfokus pada salah satu ataupun lebih dari satu sistem pada r-RST. Penelitian oleh Harbeck dan Glendon (2013) berfokus pada Behavioural Activation System (BAS) dan Behavioural Inhibition System (BIS) untuk mengetahui pengaruh antara motivasi yang ada pada kedua sistem tersebut terhadap risiko yang dirasakan pengendara terkait perilaku berisiko saat berkendara. Penelitian tersebut menggunakan SPSRQ dan hasil penelitian menemukan bahwa apabila seseorang semakin senstitif terhadap hukuman, orang tersebut akan merasakan risiko yang semakin besar untuk melakukan perilaku berkendara yang berisiko. Akan tetapi, berbeda dengan penelitian sebelumnya, Castellà dan Pérez (2004) tidak menemukan adanya hubungan atau pengaruh yang signifikan antara sensitivitas seseorang pada hukuman terhadap perilaku berkendara yang menyimpang. Metode RST dan CDT pada penelitian ini digunakan untuk mengatasi kekurangan TPB dan DBQ yang ridak dapat melihat persepsi hukuman atau sanksi hukum.

\section{METODOLOGI}

\section{A. Subyek Penelitian}

Penelitian ini berfokus pada perilaku pengendara di jalan, khususnya dalam melakukan perilaku mengebut di Indonesia. Oleh karena itu, kriteria responden yang dipilih untuk mengisi kuesioner adalah berkewarganegaraan Indonesia dan memiliki Surat Izin Mengemudi (SIM) A, B, C, atau D. Didapatkan 317 responden, dengan kriteria yang memenuhi, mengisi kuesioner yang disebarkan secara daring. Responden tersebut terdiri dari 111 (35\%) laki-laki dan 206 (85\%) perempuan dengan rentang usia dari 17 sampai 56 tahun. Apabila dikelompokkan berdasarkan usia, maka responden dapat dibagi menjadi tiga kelompok yaitu kelompok dewasa muda (17-25 tahun; 74,4\%), dewasa (25-35 tahun; 22,1\%), dan paruh baya (36-56 tahun; 3,5\%). Demografi lebih lanjut dapat dilihat pada Tabel 1.

Tabel 1

Demografi Responden

\begin{tabular}{|c|c|c|c|}
\hline & & & \\
\hline Keterangan & Kategori & $\mathrm{N}$ & $\%$ \\
\hline Jenis Kelamin & Laki-laki & 111 & 35,0 \\
\hline & Perempuan & 206 & 65,0 \\
\hline Usia & 17-25 tahun & 236 & 74,7 \\
\hline & 25-35 tahun & 70 & 22,1 \\
\hline & 36-56 tahun & 11 & 3,5 \\
\hline Pekerjaan & Pelajar/mahasiswa & 208 & 65,6 \\
\hline & Bekerja & 98 & 31,0 \\
\hline & Lainnya & 11 & 3,4 \\
\hline Pendidikan Terakhir & Sekolah Menengah Atas & 147 & 46,4 \\
\hline & S1 & 135 & 42,6 \\
\hline & Lainnya (SMP/D1/D3/D4/S2) & 35 & 11,0 \\
\hline Domisili & Sumatra & 25 & 7,9 \\
\hline & Jawa & 274 & 86,4 \\
\hline & Kalimantan & 10 & 3,2 \\
\hline & Lainnya & 8 & 2,5 \\
\hline Surat Izin Mengemudi (SIM) & SIM A & 39 & 12,3 \\
\hline & SIM B & 1 & 0,3 \\
\hline & SIM C & 159 & 50,2 \\
\hline & SIM D & 1 & 0,3 \\
\hline & Lebih dari 1 & 116 & 36,6 \\
\hline Pengalaman Berkendara & Kurang dari 6 tahun & 131 & 41,3 \\
\hline & $6-10$ tahun & 147 & 46,6 \\
\hline & $11-15$ tahun & 32 & 10,1 \\
\hline & Lebih dari 16 tahun & 7 & 2,2 \\
\hline Jarak Tempuh per Hari & Kurang dari 11 km & 164 & 51,7 \\
\hline & $11-25 \mathrm{~km}$ & 84 & 26,5 \\
\hline & $26-55 \mathrm{~km}$ & 56 & 17,7 \\
\hline & Lebih dari $55 \mathrm{~km}$ & 13 & 4,1 \\
\hline Jenis Kendaraan & Sepeda motor & 188 & 59,3 \\
\hline & Mobil penumpang & 34 & 10,7 \\
\hline & Sepeda motor dan mobil penumpang & 85 & 26,8 \\
\hline & Lainnya & 10 & 3,2 \\
\hline Riwayat tilang akibat melebihi & Tidak pernah & 315 & 99,4 \\
\hline batas kecepatan jalan & Pernah & 2 & 0,6 \\
\hline
\end{tabular}




\section{B. Desain Kuesioner}

Kuesioner yang digunakan pada penelitian ini berisi beberapa aspek yang dapat mempengaruhi perilaku mengebut pengendara. Kuesioner ini terdiri dari tiga bagian. Bagian pertama berisi pertanyaan terkait demografi. Bagian kedua berisi pertanyaan terkait SPSRQ (Logan dkk., 2019) yang terdiri dari dua variabel yaitu sensitivity to rewards (SR; seberapa sensitif pengendara terhadap imbalan) dan sensitivity to punishment (SP; seberapa sensitif pengendara terhadap sanksi). Bagian ketiga berisi pertanyaan berdasarkan TPB, DBQ, dan CDT. Terkait TPB (Javid \& Al-Hashimi, 2020; Atombo dkk., 2019; De Pelsmacker \& Janssens, 2007), terdapat variabel subjective norm ( $\mathrm{SN}$; pendapat subjektif orang disekeliling pengendara terhadap perilaku ngebut), attitude (A; sikap pengendara terhadap perilaku mengebut), perceived behavioural control (PBC; persepsi pengendara tentang fasilitas yang mendukung maupun menghambat perilaku mengebut), intention (I; keinginan pengendara untuk melakukan perilaku ngebut) dan behaviour (perilaku mengebut secara umum). Kemudian DBQ (Al-Matawaha dkk., 2020; Atombo dkk., 2016) terdiri dari mistakes (M; seberapa sering melakukan perilaku mistakes yang berhubungan dengan ngebut), deliberate violations (DV; seberapa sering melakukan pelanggaran yang disengaja yang berhubungan dengan ngebut), dan unintended violations (UV; seberapa sering melakukan pelanggaran yang tidak disengaja yang berhubungan dengan ngebut). Terakhir, CDT (Truelove dkk., 2017) terdiri dari certainty (C; kepastian sanksi), severity (SV; dampak sanksi), swiftness (SW; kecepatan pemberian sanksi). Pertanyaan-pertanyaan ini menggunakan skala Likert 1-5 sebagai pengukur respon dari responden.

\section{Prosedur Penelitian}

Metode pengambilan data pada penelitian ini adalah dengan menggunakan kuesioner daring. Pada tahapan pengembangan, kuesioner disebar kebeberapa responden terlebih dahulu untuk memastikan bahwa pertanyaan-pertanyaan pada kuesioner sudah jelas dan tidak ambigu (valid dan reliabel). Setelah itu, kuesioner disebar secara daring melalui Google Form untuk mendapatkan jumlah responden yang dibutuhkan. Pada penelitian ini, jumlah minimal sampel yang dibutuhkan dihitung berdasarkan estimasi "10-times rule' (Hair dkk., 2011). Analisis pada penelitian ini dilakukan dengan bantuan software Statistical Package for Social Scientist (SPSS) untuk data demografi dan menggunakan metode analisis regresi linier berganda. Sedangkan data lainnya diolah menggunakan software SmartPLS 3 dengan metode Partial Least Squares Equation Modelling (PLS-SEM). Metode ini dipilih karena metode ini dapat melakukan pengujian hubungan struktural atau hubungan antar beberapa variabel secara simultan. Metode ini juga mampu melakukan analisis walaupun dengan jumlah data yang sedikit dan tidak normal.

\section{HASIL DAN DISKUSI}

Sebelum dilakukan uji regresi linier, dilakukan uji asumsi klasik terlebih dahulu. Berdasarkan uji asumsi tersebut, data demografi memenuhi asumsi normalitas, tidak memiliki gejala multikolinearitas, tidak terdapat gejala heteroskedastisitas dan tidak memiliki gejala autokorelasi. Hasil dari uji F menunjukkan bahwa semua variabel demografi secara simultan dapat mempengaruhi perilaku mengebut. Sedangkan hasil dari uji t menunjukkan bahwa yang memiliki pengaruh terhadap perilaku mengebut adalah jenis kelamin, SIM, dan ratarata jarak yang ditempuh pengendara per harinya. Arah pengaruh jenis kelamin dan SIM adalah negatif sedangkan jarak memiliki arah yang positif. Sehingga dapat dikatakan bahwa laki-laki lebih memiliki kecenderungan untuk ngebut daripada perempuan. Terkait SIM, yang cenderung memiliki perilaku ngebut adalah pengemudi yang memiliki SIM A. Kemudian terkait rata-rata jarak yang ditempuh per harinya, semakin jauh jarak yang ditempuh pengendara semakin besar kecenderungan pengendara untuk melakukan perilaku ngebut.

Terkait data yang diolah pada SmartPLS, nilai $R$-Square dapat dilihat pada Tabel 2. Semua variabel dari teori TPB memiliki pengaruh yang signifikan terhadap variabel intention. Variabel intention juga memiliki pengaruh yang signifikan terhadap variabel behaviour. Hal ini sesuai dengan penelitian-penelitian sebelumnya (Atombo dkk., 2016; Boisson dkk., 2019; Wallén Warner \& Åberg, 2008). Variabel PBC memiliki kontribusi terbesar terhadap niatan sesesorang dalam melakukan perilaku mengebut (intention) sehungga hasil ini berbeda dengan penelitian oleh Forward (2009) yang menyatakan bahwa faktor yang paling mempengaruhi niat mengebut adalah sikap mengebut (attitude). Indikator pada variabel PBC yang memiliki nilai koefisien 
tertinggi adalah "Karena saya sudah berpengalaman dalam berkendara, mudah bagi saya untuk mengebut". Hubungan antara variabel PBC dengan variabel intention adalah positif. Semakin banyak sumber daya dan motivasi yang mendukung, serta semakin sedikit hambatan yang dirasakan pengendara, semakin besar kontrol perilaku yang mereka rasakan. Dengan begitu, dapat diartikan bahwa semakin pengendara merasa memiliki kontrol terhadap kendaraannya (misalnya semakin berpengalaman), maka semakin besar kemungkinan seseorang untuk mengebut.

Tabel 2

Nilai $R$-Square

\begin{tabular}{lcc}
\hline \multicolumn{1}{c}{ Variabel } & R-Square & R-Square Adjusted \\
\hline Behaviour (B) & 0,408 & 0,394 \\
Deliberate Violation (DV) & 0,331 & 0,329 \\
Intention (I) & 0,403 & 0,397 \\
Mistakes (M) & 0,192 & 0,189 \\
Unintended Violation (UV) & 0,117 & 0,115 \\
\hline
\end{tabular}

Variabel A dan variabel SN juga memiliki hubungan yang positif terhadap variabel intention. Hal ini selaras dengan penelitian oleh Javid dan Al-Hashimi (2020), Atombo dkk. (2016), dan De Pelsmacker dan Janssens (2007). Hasil penelitian ini menunjukkan bahwa pengendara di Indonesia memiliki sikap terhadap perilaku mengebut sesuai dengan indikator "Semua orang harus mematuhi batas kecepatan maksimal yang ada di jalan untuk keamanan bersama" dengan nilai koefisien $0,862(\mathrm{M}=4,426$; $\mathrm{SD}=0,856)$ dan "Saya percaya bahwa mengebut (melebihi batas kecepatan maksimal) dapat mengakibatkan kecelakaan" dengan nilai koefisien $0,804(\mathrm{M}=4,495 ; \mathrm{SD}=0,794)$. Sedangkan untuk indikator yang memiliki nilai koefisien tertinggi pada variabel SN adalah "Menurut saya, saudara saya setuju kalau saya mengemudi di atas batas kecepatan maksimal kendaraan", yaitu sebesar 0,883 dengan rata-rata pengendara menjawab tidak setuju $(\mathrm{M}=1,878$; SD $=0,429)$. Sehingga, berdasarkan kedua hal tersebut, meskipun pengendara memiliki kepercayaan bahwa semua orang perlu mematuhi batas kecepatan yang ada di jalan, perilaku mengebut dapat mengakibatkan kecelakaan, dan orang-orang disekitarnya juga tidak setuju dengan perilaku mengebut, pada tingkatan tertentu, terdapat kemungkinan bahwa pengendara tetap akan melakukan perilaku mengebut. Semua hasil yang didapatkan selaras dengan pernyataan Ajzen (1991). Ajzen menyatakan, semakin baik sikap dan norma subjektif terhadap perilaku tersebut, dan semakin besar kontrol perilaku yang dirasakan seorang individu, semakin kuat niatan individu untuk melakukan perilaku tersebut. Sehingga rekomendasi pencegahan yang dapat diberikan berdasarkan hal tersebut adalah dengan menambahkan hambatan bagi pengendara dalam melakukan perilaku mengebut.

Selanjutnya, variabel intention memiliki hubungan yang positif terhadap ketiga variabel DBQ. Hal ini sesuai dengan penelitian oleh Atombo dkk. (2016). Selain itu, nilai effect size variabel intention terhadap variabel DV juga tinggi $\left(f^{2}=0,495\right)$, sedangkan terhadap variabel $\mathrm{M}$ termasuk sedang $\left(f^{2}=0,238\right)$ dan terhadap variabel UV termasuk rendah $\left(f^{2}=0,133\right)$. Sehingga berdasarkan penelitian ini dan penelitian Atombo dkk. (2016), niatan mengebut dapat memprediksi perilaku pengendara yang menyimpang, terutama secara disengaja (deliberate). Dengan kata lain, perilaku mengebut identik dengan perilaku menyimpang yang disengaja. Oleh karena itu, dibutuhkan hambatan yang dapat mencegah pengendara secara sengaja mengebut.

Terkait CDT, dari ketiga variabel tersebut yang memiliki pengaruh yang signifikan terhadap perilaku mengebut hanyalah variabel SW. Variabel SW hanya memiliki satu indikator yaitu "Waktu antara ketahuan mengebut dan menerima sanksi sangat lah singkat". Hal ini bertentangan dengan penelitian oleh Truelove dkk. (2017) yang menyatakan bahwa variabel SW tidak memiliki pengaruh yang signifikan terhadap perilaku mengebut, akan tetapi konsisten dengan penelitian oleh Nagin dan Pogarsky (2001) dan Fleiter dan Watson (2006). Hasil yang signifikan ini menunjukkan bahwa sanksi yang diberikan kepada pelanggar sebaiknya diberikan sesegera mungkin untuk mencegah perilaku mengebut. Hubungan yang negatif pada variabel swiftness menunjukkan bahwa semakin singkat penerapan hukuman atau sanksi diberikan kepada pengendara yang mengebut melampaui batas kecepatan, semakin besar kemungkinan pelanggar menyadari bahwa lebih banyak kerugian daripada keuntungan yang akan didapatkan ketika melakukan perilaku tersebut. Hasil yang tidak signifikan untuk varibel lainnya dapat diakibatkan karena hubungan yang fluktuatif terhadap waktu seperti yang dapat dilihat pada hasil analisis yang dikemukakan oleh Truelove dkk. (2020). Selain itu, fakta bahwa hanya 2 orang dari 317 responden yang pernah ditilang karena melakukan mengebut menunjukkan bahwa sanksi hukum terhadap perilaku mengebut tersebut tidak pasti. Padahal berdasarkan laporan responden, 
$22,4 \%$ responden berkendara dengan kecepatan rata-rata di atas batas kecepatan jalan antarkota, 40,7\% responden berkendara di atas batas kecepatan jalan perkotaan, dan 36,3\% responden berkendara di atas batas kecepatan jalan permukiman. Agar variabel certainty dan severity dapat memberikan pengaruh yang signifikan, hendaknya sanksi hukum selalu diberikan karena polisi adalah otoritas hukum yang dapat memanipulasi kepastian dari pemberian sanksi kepada pelanggar (Simpson dkk., 2020).

Dua variabel pada SPSRQ memiliki nilai koefisien yang negatif. Menurut penelitian oleh Logan dkk. (2019), variabel SP memiliki hubungan yang negatif terhadap perilaku mengebut sedangkan variabel SR kebalikannya. Sehingga, hasil untuk variabel SR tidak sesuai dengan penelitian sebelumnya. Selain itu, kedua variabel juga tidak memiliki pengaruh yang signifikan. Sehingga hubungan negatif yang telah disebutkan menjadi tidak penting. Hasil yang diperoleh dapat terjadi karena respon yang diberikan oleh pengendara menunjukkan bahwa pengendara tidak terlalu sensitif terhadap penghargaan. Jika melihat koefisien yang didapatkan, diantara kedua variabel tersebut yang memiliki nilai koefisien yang terbesar, dalam hal ini berarti nilai negatif terbesar, adalah variabel SP. Hal ini menunjukkan bahwa pengendara sebenarnya lebih sensitif terhadap hukuman daripada terhadap penghargaan. Pencegahan yang dapat dilakukan adalah dengan memberikan sanksi yang berat (berdampak buruk) pada pengendara yang melakukan perilaku mengebut di atas batas kecepatan maksimal yang ada di jalan. Berdasarkan uraian tersebut, maka model empiris perilaku mengebut dapat dilihat pada Gambar 1 .

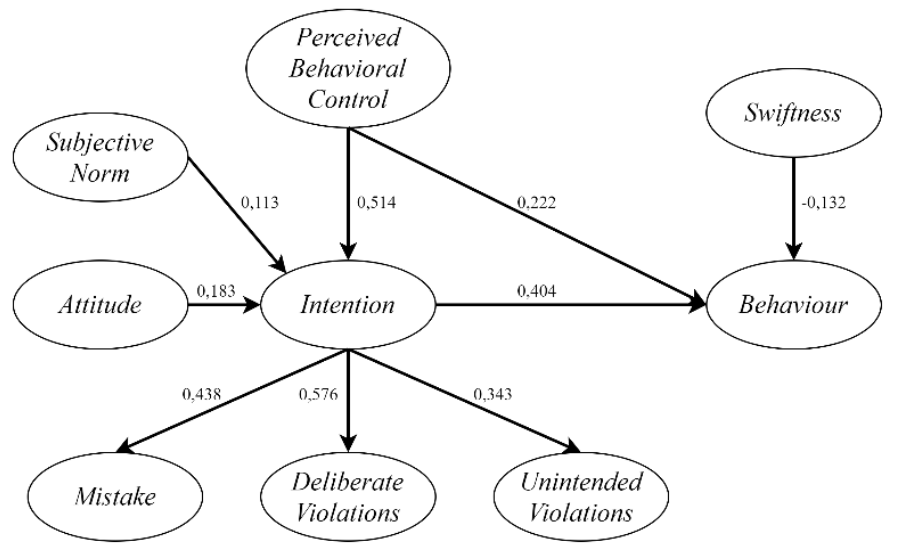

Gambar 1. Model Empiris Perilaku Mengebut

\section{KESIMPULAN}

Berdasarkan hasil penelitian yang telah didapatkan serta pembahasan yang dilakukan, kesimpulan dari penelitian ini adalah sebagai berikut:

1) Faktor-faktor yang mempengaruhi perilaku mengebut secara signifikan adalah jenis kelamin, SIM, rata-rata jarak yang ditempuh pengendara per harinya, intention (niat melakukan perilaku mengebut), perceived behavioural control (kontrol perilaku yang dirasakan pengendara), attitude towards behaviour (sikap terhadap perilaku), subjective norm (norma subjektif), dan swiftness (kecepatan diberikannya sanksi) dengan perceived behavioural control sebagai variabel yang paling berpengaruh.

2) Rekomendasi pencegahan yang dapat dilakukan dengan mengetahui faktor-faktor tersebut yaitu memberikan hambatan agar pengendara tidak merasa terfasilitasi untuk melakukan perilaku mengebut, memberikan sanksi hukum sesegera mungkin bagi pengendara yang melakukan pelanggaran atau melebihi batas kecepatan maksimal yang ada di jalan, dan memberikan sanksi yang pasti dan cukup berdampak bagi pelanggar karena pelanggar lebih sensitif terhadap hukuman berdasarkan analisis deskriptif dan nilai outer loading yang didapatkan. Hal ini karena semua variabel yang signifikan berpengaruh positif terhadap niat dan perilaku mengebut kecuali variabel swiftness. 


\section{DAFTAR PUSTAKA}

Mola, T., Tolok, A. D., \& Maskur, M. F. (2019). Penjualan Sepeda Motor 2018, Indonesia Tembus Pasar Terbesar di Asean. Infografik. https://infografik.bisnis.com/read/20190116/547/879292/penjualan-sepedamotor-2018-indonesia-tembus-pasar-terbesar-di-asean.

Badan Pusat Statistik. (2018). Perkembangan Jumlah Kendaraan Bermotor Menurut Jenis, 1949-2018. https://www.bps.go.id/indicator/17/57/1/jumlah-kendaraan-bermotor.html.

Samudra, M. A., \& Wijaya, I. (2020). Angka Kematian Kecelakaan Lalu Lintas di Indonesia Tinggi, Tiap Satu Jam Tiga Orang Tewas. Otomotif. https://otomotifnet.gridoto.com/read/232051060/angka-kematiankecelakaan-lalu-lintas-di-indonesia-tinggi-tiap-satu-jam-tiga-orang-tewas.

Indriastuti, A. K., \& Sulistio, H. (2010). Influencing factors on motorcycle accident in urban area of Malang, Indonesia. International Journal of Academic Research, 2(5), 252-255.

Atombo, C., Wu, C., Zhong, M., \& Zhang, H. (2016). Investigating the motivational factors influencing drivers intentions to unsafe driving behaviours: Speeding and overtaking violations. Transportation Research Part F: Traffic Psychology and Behaviour, 43, 104-121.

Boissin, C., Al Maniri, A. A., Al-Azri, A. S., Hasselberg, M., \& Laflamme, L. (2019). Determinants of speeding among new generations of car drivers from the Arabian Peninsula. An investigation based among Omani drivers using the theory of planned behaviour. PLoS ONE, 14(12), 1-14.

Javid, M. \& Al-Hashimi, A. (2020). Significance of attitudes, passion, and cultural factors in driver's speeding behaviour in Oman: application of theory of planned behaviour. International Journal of Injury Control and Safety Promotion, 27, 172-180.

Forward, S. E. (2009). The theory of planned behaviour: The role of descriptive norms and past behaviour in the prediction of drivers' intentions to violate. Transportation Research Part F: Traffic Psychology and Behaviour, 12(3), 198-207.

Al-Matawaha, J. al, Jadaan, K., \& Freeman, B. (2020). Analysis of speed related behavior of kuwaiti drivers using the driver behavior questionnaire. Periodica Polytechnica Transportation Engineering, 48(2), 150158 .

Trapsilawati, F., Priatna, N. U., Wijayanto, T., Widyanti, A., Syafitri, U. D., \& Chamidah, N. (2021). Examining driver's socio-demographic variables and perceptions towards sanction mechanisms on speeding behaviour on highways: targeting appropriate prevention. The Journal of Navigation, 1, 1-12.

Truelove, V., Freeman, J., Szogi, E., Kaye, S., Davey, J., \& Armstrong, K. (2017). Beyond the threat of legal sanctions: What deters speeding behaviours? Transportation Research Part F: Traffic Psychology and Behaviour, 50, 128-136.

Truelove, V., Freeman, J., Watson, B., Kaye, S., \& Davey, J. (2020). Are perceptions of penalties stable across time? The problem of causal ordering in deterrence applied to road safety. Accident Analysis and Prevention, 146, 105746.

Harbeck, E. L., \& Glendon, A. I. (2013). How reinforcement sensitivity and perceived risk influence young drivers' reported engagement in risky driving behaviors. Accident Analysis and Prevention, 54, 73-80.

Castellà, J. \& Pérez, J. (2004). Sensitivity to punishment and sensitivity to reward and traffic violation. Accident Analysis and Prevention, 36, 947-952.

De Pelsmacker, P. dan Janssens, W. (2007). The Effect of Norms, Attitudes and Habits on Speeding Behavior: Scale Development and Model Building and Estimation. Accident Analysis and Prevention, 39, 6-15.

Wallén Warner, H. dan Åberg, L. (2008). Drivers' beliefs about exceeding the speed limits. Transportation Research Part F: Traffic Psychology and Behaviour, 11, 376-389.

Hair, J. F., Ringle, C. M., \& Sarstedt, M. (2011). PLS-SEM: Indeed a silver bullet. Journal of Marketing Theory and Practice, 19(2): 139-152.

Nagin, S. dan Pogarsky, G. (2001). Integrating celerity, impulsivity, and extralegal sanction threats into a model of general deterrence: Theory and evidence. Criminology, 39, 865-889.

Ajzen, I. (1991). The Theory of Planned Behaviour. Organizational Behavior and Human Decision Processes, $50,179-211$.

Fleiter, J., \& Watson, B. (2006). The speed paradox: The misalignment between driver attitudes and behaviours. Journal of the Australasian College of Road Safety, 17, 23-30.

Logan, E., Kaye, S. A., \& Lewis, I. (2019). The influence of the revised reinforcement sensitivity theory on risk perception and intentions to speed in young male and female drivers. Accident Analysis and Prevention, 132(Juli), 105291. 